\title{
Understanding effective diameter and its application to terrestrial radiation in ice clouds
}

\author{
D. L. Mitchell ${ }^{1}$, R. P. Lawson ${ }^{2}$, and B. Baker ${ }^{2}$ \\ ${ }^{1}$ Division of Atmospheric Sciences, Reno, NV 89512-1095, USA \\ ${ }^{2}$ SPEC, Inc., 5401 Western Ave., Boulder, CO 80301, USA \\ Received: 3 October 2010 - Published in Atmos. Chem. Phys. Discuss.: 2 December 2010 \\ Revised: 22 March 2011 - Accepted: 24 March 2011 - Published: 11 April 2011
}

\begin{abstract}
The cloud property known as "effective diameter" or "effective radius", which in essence is the cloud particle size distribution (PSD) volume at bulk density divided by its projected area, is used extensively in atmospheric radiation transfer, climate modeling and remote sensing. This derives from the assumption that PSD optical properties can be uniquely described in terms of their effective diameter, $D_{\mathrm{e}}$, and their cloud water content (CWC), henceforth referred to as the $D_{\mathrm{e}}$-CWC assumption. This study challenges this assumption, showing that while the $D_{\mathrm{e}}$-CWC assumption appears generally valid for liquid water clouds, it appears less valid for ice clouds in regions where (1) absorption is not primarily a function of either the PSD ice water content (IWC) or the PSD projected area, and (2) where wave resonance (i.e. photon tunneling) contributes significantly to absorption. These two regions often strongly coincide at terrestrial wavelengths when $D_{\mathrm{e}}<\sim 60 \mu \mathrm{m}$, which is where this $D_{\mathrm{e}}$-CWC assumption appears poorest. Treating optical properties solely in terms of $D_{\mathrm{e}}$ and IWC may lead to errors up to $24 \%, 26 \%$ and $20 \%$ for terrestrial radiation in the window region regarding the absorption and extinction coefficients and the single scattering albedo, respectively. Outside the window region, errors may reach $33 \%$ and $42 \%$ regarding absorption and extinction. The magnitude and sign of these errors can change rapidly with wavelength, which may produce significant errors in climate modeling, remote sensing and other applications concerned with the wavelength dependence of radiation.

Where the $D_{\mathrm{e}}-\mathrm{CWC}$ assumption breaks down, ice cloud optical properties appear to depend on $D_{\mathrm{e}}$, IWC and the PSD shape. Optical property parameterizations in climate mod-
\end{abstract}

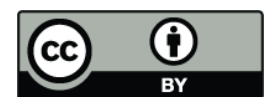

Correspondence to: D. L. Mitchell (mitch@dri.edu) els and remote sensing algorithms based on historical PSD measurements may exhibit errors due to previously unknown PSD errors (i.e. the presence of ice artifacts due to the shattering of larger ice particles on the probe inlet tube during sampling). More recently developed cloud probes are designed to mitigate this shattering problem. Using realistic PSD shapes for a given temperature (and/or IWC) and cloud type may minimize errors associated with PSD shape in ice optics parameterizations and remote sensing algorithms.

While this topic was investigated using two ice optics schemes (the Yang et al., 2005 database and the modified anomalous diffraction approximation, or MADA), a physical understanding of the limitations of the $D_{\mathrm{e}}$-IWC assumption was made possible by using MADA. MADA allows one to approximate the contribution of photon tunneling to absorption relative to other optical processes, which reveals that part of the error regarding the $D_{\mathrm{e}}$-IWC assumption can be associated with tunneling. By relating the remaining error to the radiation penetration depth in bulk ice $(\Delta L)$ due to absorption, the domain where the $D_{\mathrm{e}}$-IWC assumption is weakest was described in terms of $D_{\mathrm{e}}$ and $\Delta L$.

\section{Introduction}

The concept of an effective diameter has found broad acceptance and usage in atmospheric radiation transfer in describing cloud optical properties and in remote sensing applications. For example, liquid water and ice cloud optical properties are generally parameterized in two-stream radiation transfer models in terms of an effective diameter $D_{\mathrm{e}}$ and the cloud water content (e.g. Slingo and Schrecker, 1982; Slingo, 1989; Fu, 1996; Fu et al., 1998; Yang et al., 2001; Yang et al., 2005), although Hansen and Travis (1974) have

Published by Copernicus Publications on behalf of the European Geosciences Union. 
shown that to accurately calculate cloud optical properties, the effective variance of the size distribution is often needed. For ice clouds $D_{\mathrm{e}}$ has multiple definitions (McFarquhar et al., 1998), and the definition used in this study is

$D_{\mathrm{e}}=(3 / 2) \mathrm{WC} / \rho \mathrm{P}$,

where WC is condensed water content, $\rho$ is bulk density for liquid water $\left(1.0 \mathrm{~g} \mathrm{~cm}^{-3}\right)$ or ice $\left(0.917 \mathrm{~g} \mathrm{~cm}^{-3}\right)$ and $\mathrm{P}$ is the projected area of the particle size distribution. This definition is appropriate for water, ice and mixed phase clouds (Mitchell 2002, henceforth M2002).

In liquid water clouds for both solar and terrestrial radiation, numerical solutions for the absorption coefficient $\beta_{\mathrm{abs}}$ using Mie theory are generally almost identical to $\beta_{\text {abs }}$ determined using Mie theory to calculate the absorption efficiency (i.e. absorption cross-section/particle projected area) of $D_{\mathrm{e}}$ (for the same droplet size distribution) multiplied by the size distribution projected area (M2002). Thus $D_{\mathrm{e}}$ is not an arbitrary size but holds physical meaning, and can be understood as the representative photon path for all particles in a size distribution (M2002).

In M2002 it was shown that two ice particle size distributions (PSDs) having the same $D_{\mathrm{e}}$ and IWC can have substantially different optical properties at terrestrial wavelengths, such as when one PSD is exponential and the other is bimodal. These differences were $100 \%$ or more for extinction in the far infrared $\left(50 \mu \mathrm{m}<\lambda<1000 \mu \mathrm{m}, D_{\mathrm{e}}=26 \mu \mathrm{m}\right)$, indicating considerable uncertainty may exist for radar-lidar cloud property retrievals. Similarly, the cloud radar backscatter is likely to vary by a factor of 7 or more for similar values of the PSD volume diameter and IWC (Sun et al., 2011, Fig. 8). However, it has not been clear whether this presented serious problems for commonly used ice cloud optical property schemes since the optics parameterizations were "tuned" to PSD believed to be representative of cirrus clouds.

The parameterization of ice cloud optical properties generally follows these three steps: (1) Calculation of single ice crystal optical properties from electrodynamic theory for size parameter $x<\sim 20$, from a form of geometric optics for $x>\sim 60$, and from a "bridging" parameterization linking these two x regimes (e.g. Yang et al., 2005); (2) integration of optical properties for single ice crystals over the PSD to obtain the coefficients of extinction and absorption and the single scattering albedo for the PSD; and (3) relating the PSD optical properties to the $D_{\mathrm{e}}$ and ice water content (IWC) of the PSD through empirical means such as curve-fitting. For step 3 to be conceptually valid, $D_{\mathrm{e}}$ and IWC must uniquely define the PSD optical properties, regardless of PSD shape. In M2002, it was shown that this was not universally valid. But since step 3 tunes the optics parameterization to PSD characteristic of cirrus clouds, the optics schemes may yield reasonable results, provided the PSD parameterizing the ice optics are representative of most cirrus clouds.

More recently it has been shown that historical cirrus PSD measurements have been contaminated by ice particles that shatter when impacting the probe inlet tube in the case of the Forward Scattering Spectrometer Probe (FSSP) (Knollenberg 1981) or the Cloud Aerosol Spectrometer (CAS) (Baumgardner et al., 2001) that measure the smaller ice particles (maximum dimension $D<60 \mu \mathrm{m}$ ) (McFarquhar et al., 2007; Jensen et al., 2009). Shattering on the probe arms also produces relatively small ice artifacts, but to a lesser extent, in the case of the 2-D-Cloud probe (Korolev and Isaac, 2005; Field et al., 2006). In addition, satellite measurements have provided evidence that historical cirrus PSD measurements are often having small ice crystal concentrations 1 or 2 orders of magnitude greater than those retrieved from satellite for a given IWC (Mitchell et al., 2010). Recent changes in probe design (e.g. McFarquhar et al., 2007; Korolev et al., 2010) and electronic detection of ice artifacts due to shattering (Baker et al., 2009a, b; Jensen et al., 2009; Lawson et al., 2010) have greatly reduced the amount of ice artifacts, often lowering small ice crystal concentrations by 1 to 2 orders of magnitude (McFarquhar et al., 2007; Jensen et al., 2009). These instrument modifications appear to result in changes to PSD shape. Thus it appears prudent now to ask the question: What effect, if any, will this change in PSD shape have on parameterized optical properties?

This study will investigate to what extent ice cloud optical properties are likely to vary due to changes in PSD shape when $D_{\mathrm{e}}$ and IWC are held constant. This will be investigated using PSD measurements from two recent field studies where the shattering problem has been minimized, as described in Sect. 2. The optical properties from these PSD are compared to those from PSD having a different shape but having the same $D_{\mathrm{e}}$ and IWC. Section 3 will discuss the conditions under which ice cloud optical properties may not be well defined by $D_{\mathrm{e}}$ and IWC. A summary and implications of this work are discussed in Sect. 4.

\section{Optical properties of cirrus PSD having the same $D_{\mathrm{e}}$ and IWC}

In this section we evaluate the optical properties of PSD having the same $D_{\mathrm{e}}$ and IWC but different PSD shapes. PSDs from two recent field campaigns are examined: (1) anvil cirrus from the Tropical Composition, Cloud and Climate Coupling (TC4) campaign, sampled in August 2007 near Costa Rica (funded by NASA), and (2) Arctic cirrus sampled during the Indirect and Semi-Direct Aerosol Campaign (ISDAC) sampled near Barrow, Alaska in April 2009 (funded by DOE's Atmospheric Systems Research (ASR) program). In (2), the temperature range of the sampled cirrus ranged from $-25^{\circ} \mathrm{C}$ to $-40^{\circ} \mathrm{C}$. Sampling of colder clouds was not possible due to the limited altitude capability of the Convair 580 research aircraft. The Arctic cirrus PSDs were relatively broad at these temperatures, with maximum particle sizes extending out to 1 to $3 \mathrm{~mm}$ (Fig. 1). The Tropical anvil cirrus PSDs were also relatively broad within a temperature range 


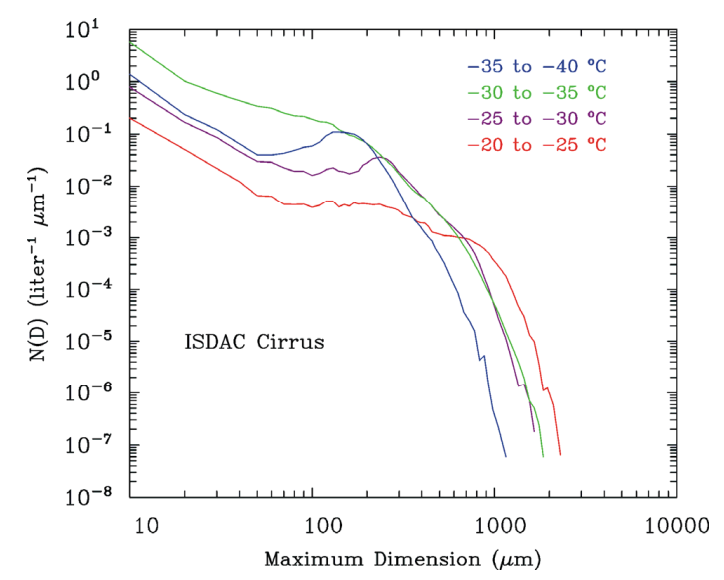

Fig. 1. Temperature dependence of Arctic cirrus PSD sampled during the ISDAC field campaign.

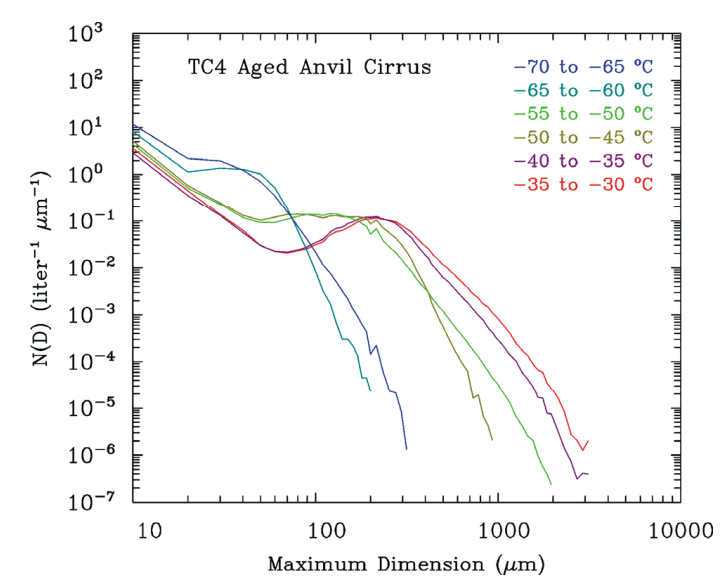

Fig. 2. Temperature dependence of aged anvil PSD sampled during the TC4 field campaign.

from $-30{ }^{\circ} \mathrm{C}$ to $-55^{\circ} \mathrm{C}$, with maximum particle sizes extending out to 1 to $3 \mathrm{~mm}$. However, the PSDs in Tropical anvil cirrus were much narrower in the temperature range from $-60^{\circ} \mathrm{C}$ to $-70^{\circ} \mathrm{C}$, with maximum particle sizes extending out to only a few hundreds of microns (Fig. 2). Figure 3 shows a similar temperature dependence for an example of PSDs measured in midlatitude cirrus clouds, sampled during the Small Particles In Cirrus (SPartICus) field campaign (funded by DOE's Atmospheric Radiation and Measurement program). This PSD evolution with temperature was often observed during SPartICus.

The feature that is common to all geographical locations is that relatively broad PSDs were observed at warmer cirrus temperatures, i.e., warmer than about $-55^{\circ} \mathrm{C}$, while relatively narrow PSDs were observed at temperatures colder than about $-60^{\circ} \mathrm{C}$. This temperature dependence may be related to ice crystal nucleation rates and the dependence of diffusional growth rates on water vapor density. However,

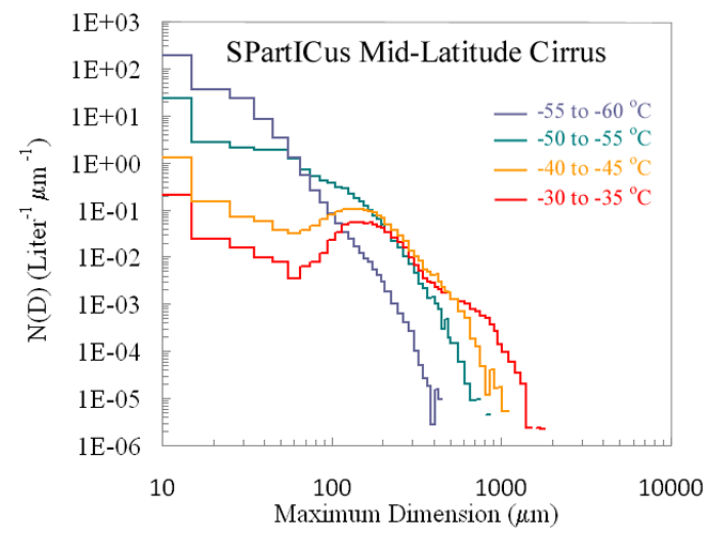

Fig. 3. An example of typical PSDs observed in moderately deep SPartICus cirrus clouds observed on 27 January and 10 February 2010 .

we do not contend that the break point between narrow and broad PSDs is universal or even consistent, because it likely depends on other factors such as the process of cirrus generation, distance from cloud top and ice particle type. Nonetheless, we observe that there does appear to be a trend whereby relatively narrow PSDs are observed at cold cirrus temperatures near cloud top, and much broader PSDs are observed at warmer cirrus temperatures lower in the cloud. This is relevant to this study since infrared radiation is absorbed differently by narrow PSDs relative to broad PSDs. These two types of PSD, narrow and broad, will be used in the Sect. 3 to illustrate three modes of absorption in cirrus clouds; volume dependent, area dependent and a transition between volume and area dependent absorption. It is noteworthy that PSD tend to evolve from narrow to broad with increasing temperature since, as will be shown in Sect. 3, this may inform us what type of absorption regime we are dealing with and how valid the $D_{\mathrm{e}}$-IWC assumption is.

In all of the above field campaigns, ISDAC, TC4 and SPartICus, the 2D-S probe developed at SPEC, Inc. (Lawson et al., 2006) was used to sample the clouds. The 2D-S directly measures ice particle length and projected area, and indirectly measures ice particle mass, as described in Sect. 2.1. The problem of ice particle shattering is greatly reduced in the 2D-S probe due to both probe design and electronic removal of shattered ice particles based on ice particle interarrival times (Lawson et al., 2006; Baker et al., 2009a, b; Lawson et al., 2010). In laboratory experiments the 2D-S probe was shown to accurately image an $8 \mu \mathrm{m}$ fiber rotating at $233 \mathrm{~m} \mathrm{~s}^{-1}$ (Lawson et al., 2006), which is greater than the true airspeeds that aircraft experienced during these field campaigns. Ice crystals smaller than this appear to have a negligible impact on most anvil cirrus optical properties (Jensen et al., 2009).

Regarding the TC4 cirrus, the NASA WB-57F and the NASA DC-8 aircraft were simultaneously sampling aged 
anvil cirrus on 5 August 2007, providing a vertical profile of PSDs. Each PSD used in this TC4 analysis corresponds to a flight leg or transect through an anvil cloud at constant temperature. These PSD were then averaged over $5^{\circ} \mathrm{C}$ temperature intervals as shown in Fig. 2. Regarding the Arctic cirrus, the Canadian Convair aircraft sampled cirrus during flights from Fairbanks to Barrow Alaska and back during the ISDAC field campaign. The ISDAC PSD used here are from 1-2 min periods of flight time where the cirrus microphysical properties (median mass dimension and extinction coefficient) were not changing rapidly over time. A total of 162 ISDAC PSD were processed from 7 different days and 9 different flights. Using measurements from the Cloud Particle Imager (CPI), the Rosemount icing rod, the relative humidity sensor and the Forward Scattering Spectrometer Probe (FSSP), no evidence of liquid water was detected in these clouds. ISDAC PSD averaged over $5{ }^{\circ} \mathrm{C}$ temperature intervals are shown in Fig. 1, where, as with Fig. 2, the average ice particle size increases with temperature.

\subsection{Comparisons with narrow PSD}

This subsection describes the development of three relatively narrow PSD having the same $D_{\mathrm{e}}$ and IWC but different PSD shapes, and characterizes their ice particle shapes analytically. The PSD representing narrow cirrus PSD in this study is the mean PSD in Fig. 2 (dark blue) corresponding to the -65 to $-70^{\circ} \mathrm{C}$ category. This serves as a reference for the other two PSD described below. This PSD has a $D_{\mathrm{e}}$ of $39.1 \mu \mathrm{m}$ and an IWC of $1.64 \mathrm{mg} \mathrm{m}^{-3}$, as shown in Fig. 4 (blue). The IWC was calculated by integrating the PSD ice particle masses, where ice particle mass was determined from 2D-S measurements of ice particle area using the mass-area relationship described in Baker and Lawson (2006). This method of IWC determination was shown to produce IWCs consistent with those measured directly by the Counterflow Virtual Impactor (CVI) during TC4 (Lawson et al., 2010; Mitchell et al., 2010). Thus the 2D-S yields measurements or estimates of the size distributions for ice particle concentration, area and mass. From the PSD IWC and total area, $D_{\mathrm{e}}$ was calculated from (1).

The green curve in Fig. 4 describes a PSD calculated from a PSD parameterization based on in situ measurements from the Central Equatorial Pacific Experiment (CEPEX) having the same $D_{\mathrm{e}}$ and IWC as the TC4 PSD (blue), where a temperature of $-65^{\circ} \mathrm{C}$ was assumed in the PSD scheme (Ivanova 2005). In this PSD scheme ice crystal sizes below $\sim 60 \mu \mathrm{m}$ were estimated from FSSP measurements, while larger ice particles were measured by the $2 \mathrm{D}-\mathrm{C}$ probe. The "small mode" concentrations in the original CEPEX PSD scheme were considerably higher than shown here, and were attenuated in this study to be $\sim 10^{2}$ higher than the highest large mode concentrations near $70 \mu \mathrm{m}$, which is more typical of PSD affected by shattering (e.g. McFarquhar et al., 2007; Jensen et al., 2009; Lawson et al., 2010). Note

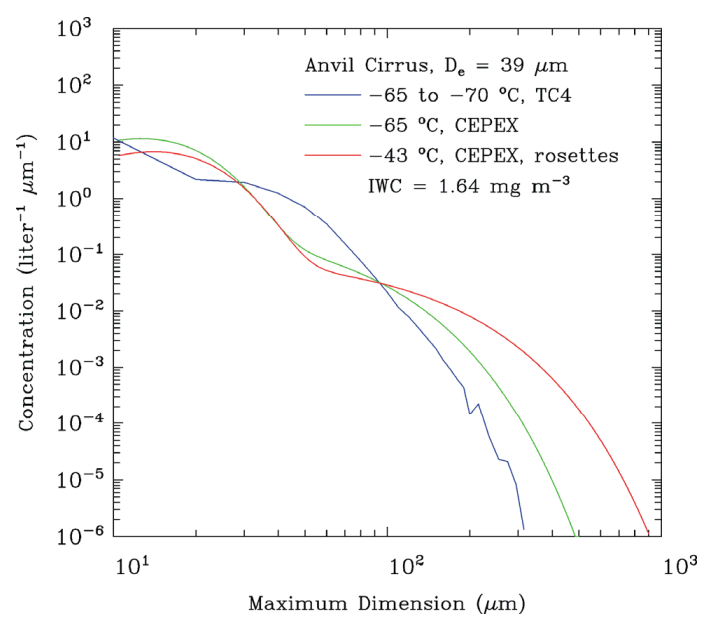

Fig. 4. Experimental design for the narrow PSD case study, based on the mean PSD sampled during TC4 between -65 and $-70^{\circ} \mathrm{C}$ (blue curve). The other two PSD were derived from a PSD scheme based on CEPEX data, evaluated at the indicated temperatures. The green curve contains approximately the same ice particle shapes (in terms of their mass and area attributes) as the measured PSD, while the red curve contains only bullet rosettes. All PSD are having the same $D_{\mathrm{e}}$ and IWC.

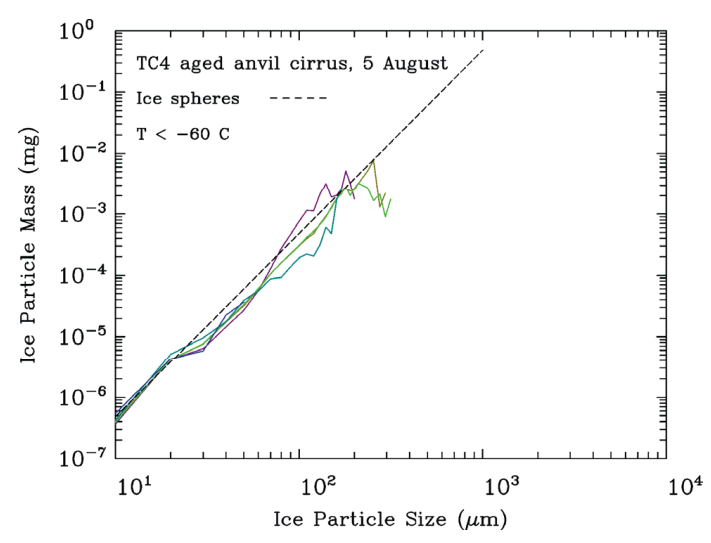

Fig. 5. Example of how ice particle area- and mass-dimension power law expressions were derived from the 2D-S data. Colored curves show the $2 \mathrm{D}-\mathrm{S}$ data while the dashed line is for ice spheres at bulk density (representing an upper limit). See text for details.

that this CEPEX PSD scheme that appears to be affected by ice artifacts from shattering is different than the CEPEX PSD scheme of McFarquhar and Heymsfield (1996). The McFarquhar-Heymsfield PSD scheme was probably not affected by the shattering problem since the small ice crystal concentrations were based on the Video Ice Particle Sampler (VIPS), which does not have an inlet tube to produce shattering artifacts.

The ice particle shapes in this CEPEX PSD were made to be roughly the same as those in the TC4 PSD in terms of their mass and area attributes. This removes ice particle 
Table 1. Projected area- and mass-dimensional power law constants for relationships of the form $A=\delta D^{\sigma}$ and $m=\alpha D^{\beta}$ that were used in this study. The power law transition dimensions for area and mass are denoted as $D_{\mathrm{a}}$ and $D_{\mathrm{m}}$, respectively. Units are cgs.

\begin{tabular}{|c|c|c|c|c|c|}
\hline \multirow[t]{2}{*}{ Conditions } & \multicolumn{4}{|c|}{ Power law constants } & \multirow[t]{2}{*}{ Valid Size Range } \\
\hline & $\delta$ & $\sigma$ & $\alpha$ & $\beta$ & \\
\hline $\mathrm{TC} 4, T<-60^{\circ} \mathrm{C}$ & 0.7209 & 2.000 & 0.1994 & 2.918 & $D_{\mathrm{a}}<235 \mu \mathrm{m}, D_{\mathrm{m}}<197 \mu \mathrm{m}$ \\
\hline Same & 0.07619 & 1.401 & 0.001188 & 1.614 & $D_{\mathrm{a}} \geq 235 \mu \mathrm{m}, D_{m} \geq 197 \mu \mathrm{m}$ \\
\hline ISDAC, -35 to $-40^{\circ} \mathrm{C}$ & 0.4977 & 2.000 & 0.1641 & 3.000 & $D_{\mathrm{a}}<279 \mu \mathrm{m}, D_{m}<242 \mu \mathrm{m}$ \\
\hline Same & 0.08240 & 1.498 & 0.001402 & 1.722 & $D_{\mathrm{a}} \geq 279 \mu \mathrm{m}, D_{m} \geq 242 \mu \mathrm{m}$ \\
\hline Bullet rosettes $^{\mathrm{a}}$ & 0.1470 & 1.750 & 0.0260 & 2.750 & $D_{\mathrm{a}}<100 \mu \mathrm{m}, D_{m}<100 \mu \mathrm{m}$ \\
\hline Same & 0.1404 & 1.740 & 0.0260 & 2.750 & $D_{\mathrm{a}} \geq 100 \mu \mathrm{m}, D_{m} \geq 100 \mu \mathrm{m}$ \\
\hline Hexagonal columns ${ }^{b}$ & 0.6837 & 2.000 & 0.2515 & 3.000 & $D_{\mathrm{a}}<100 \mu \mathrm{m}, D_{m}<100 \mu \mathrm{m}$ \\
\hline Same & 0.0459 & 1.415 & 0.001658 & 1.910 & $D_{\mathrm{a}} \geq 100 \mu \mathrm{m}, D_{m} \geq 100 \mu \mathrm{m}$ \\
\hline
\end{tabular}

${ }^{a}$ Lawson et al., 2006 (area); Heymsfield et al., 2002 (mass) ${ }^{\text {b }}$ Mitchell, 1996.

shape as a variable when comparing optical properties from these two PSD. This was done by deriving ice particle areaand mass-dimension power law relationships (henceforth A$\mathrm{D}$ and $\mathrm{m}-\mathrm{D}$ ) for the August $5^{\text {th }}$ TC4 PSD for temperatures less than $-60^{\circ} \mathrm{C}$. Since the 2D-S probe data consists of the size dependence of the ice particle number, area and mass concentration, the area concentration in each size bin can be divided by the bin number concentration to yield the mean ice particle projected area in each bin. Similarly, the mass concentration in each bin can be divided by the bin number concentration to yield the mean ice particle mass in each bin. Relating the mean areas and mean masses to bin mid-point size (i.e. ice particle maximum dimension) in log-log space, this 2D-S data can be roughly described using A-D and m$\mathrm{D}$ power laws. An example is given in Fig. 5, where the 5 PSD sampled at $T<-60^{\circ} \mathrm{C}$ are indicated by different colors. The dashed line is predicted for ice spheres at bulk density $\left(0.917 \mathrm{~g} \mathrm{~cm}^{-3}\right)$, indicating that the ice particles sampled approach that of an ice sphere having the same length. When analyzing these and other TC4 PSDs, it was found that the mass and area data was better described by two power law expressions rather than one. The A-D and $\mathrm{m}$-D power laws appropriate for $T<-60{ }^{\circ} \mathrm{C}$, along with their size range of applicability, are shown in Table 1. These relationships were used to characterize the ice particle shapes in the measured TC4 PSD (blue curve in Fig. 4) and to represent the ice particle shapes in the CEPEX PSD shown in Fig. 4 (green curve) so that both PSD are having approximately the same ice particle shapes as far as optical properties are concerned. The measured TC4 PSD contains mostly particles having $D<100 \mu \mathrm{m}$, and such ice particles are often quasi-spherical (Korolev and Isaac 2003). Thus it is not too surprising that the particle masses and areas correspond closely to ice spheres, as shown in Fig. 5. The droxtal ice crystal model (Yang et al., 2005) is a good analog for quasi-spherical ice particles.
The red PSD shown in Fig. 4 also has the same $D_{\mathrm{e}}$ and IWC as the measured PSD (blue), but the ice particle shapes correspond to bullet rosettes only. To obtain the same $D_{\mathrm{e}}$ with bullet rosettes (having less mass per unit length than the observed ice particles), the PSD from the CEPEX PSD scheme must be broader and it corresponds to $-43^{\circ} \mathrm{C}$. The A-D and $\mathrm{m}$-D relationships assumed for bullet rosettes are listed in Table 1.

\subsection{Optical properties of a narrow PSD}

In this section, optical properties are determined for the three PSD described in Sect. 2.1 and Fig. 4. For simplicity and to enable others to reproduce these results more readily, optical properties for these PSD were calculated using the ice crystal optical property database of Yang et al. (2005), which is restricted to terrestrial radiation between 3 and $100 \mu \mathrm{m}$. Refractive indexes used in all optical property calculations are from Warren and Brandt (2008). Rather than calculate the ice crystal optical properties from ice particle size, they were calculated from the ice particle volume-to-projected area ratio, or $d_{\mathrm{e}}$, where volume is evaluated at ice bulk density. To a great extent, $d_{\mathrm{e}}$ determines an ice particle's absorption and extinction efficiency (Mitchell et al. 1996; Grenfell and Warren 1999; Mitchell 2002). It depends on ice particle shape and size, and it is the relevant particle dimension in ice optics. For the measured PSD, the $d_{\mathrm{e}}$ value for each size bin was determined from the 2D-S estimates of mean bin mass and area. For the other analytical PSD, size bins of $5 \mu \mathrm{m}$ width were defined and $d_{\mathrm{e}}$ for each bin was determined from the A-D and m-D expressions. The Yang et al. database provides $d_{\mathrm{e}}$ values for each size bin, enabling a matching of PSD bin $d_{\mathrm{e}}$ values with the $d_{\mathrm{e}}$-resolved Yang ice optical properties. This matching procedure is required using $d_{\mathrm{e}}$ (as opposed to the physical particle size) in order to establish the correct "common currency" between field measurements and ice optics calculations. If this approach is not followed and the observed ice particle maximum dimension 


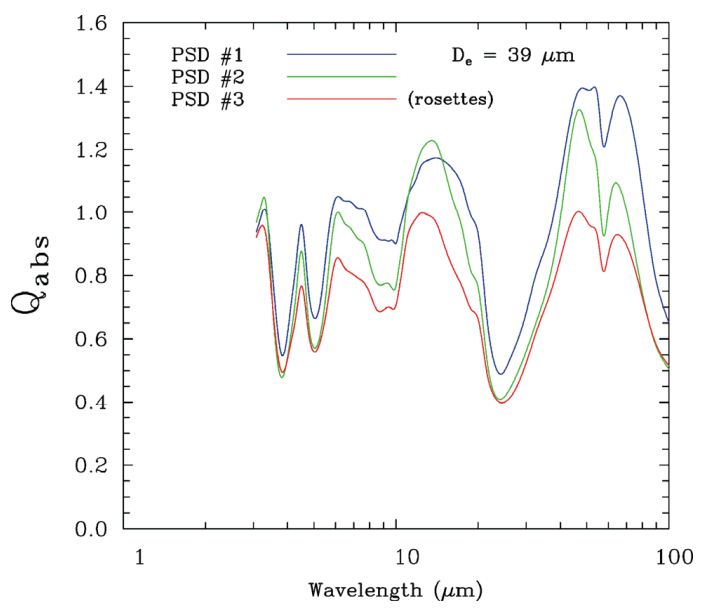

Fig. 6. Wavelength dependence of $Q_{\text {abs }}$ for the 3 PSD described in Fig. 4, using the same color convention. All PSD have the same $D_{\mathrm{e}}$ and IWC.

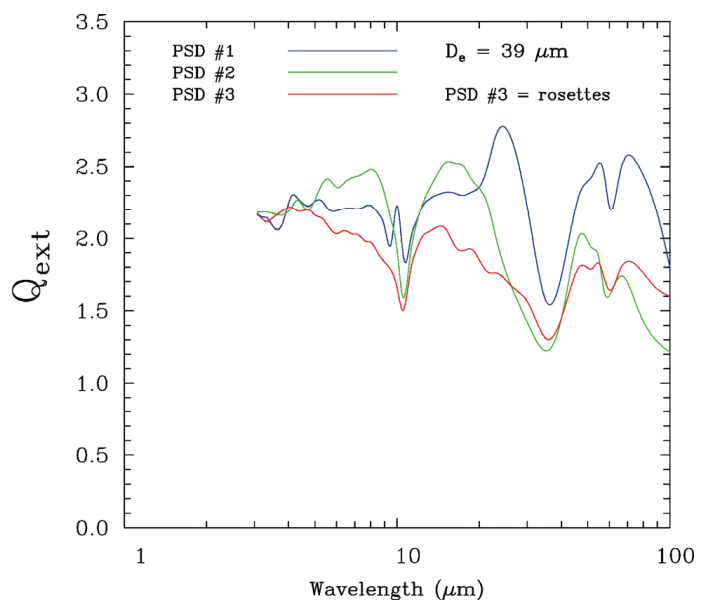

Fig. 7. Wavelength dependence of $Q_{\text {ext }}$ for the 3 PSD described in Fig. 4, using the same color convention. All PSD have the same $D_{\mathrm{e}}$ and IWC.

$D$ is matched with $D$ in the Yang et al. (2005) database, the optical properties will generally exhibit substantial errors unless $d_{\mathrm{e}}$ is conserved. In addition, the observed dominant ice particle shape should be matched with the particle shape in the Yang et al. (2005) database that most closely resembles the observed shape.

Due to the quasi-spherical nature of the ice particles sampled (see Fig. 5), the "Droxtal" crystal shape was assumed in the Yang et al. database for the two PSD containing the observed ice particle shapes while bullet rosette optical properties were used for the bullet rosette PSD. The PSD absorption and extinction efficiencies, $Q_{\text {abs }}$ and $Q_{\text {ext }}$, are plotted for the three PSD in Fig. 6 and 7. These are defined as the PSD absorption or extinction coefficient divided by PSD projected area, or

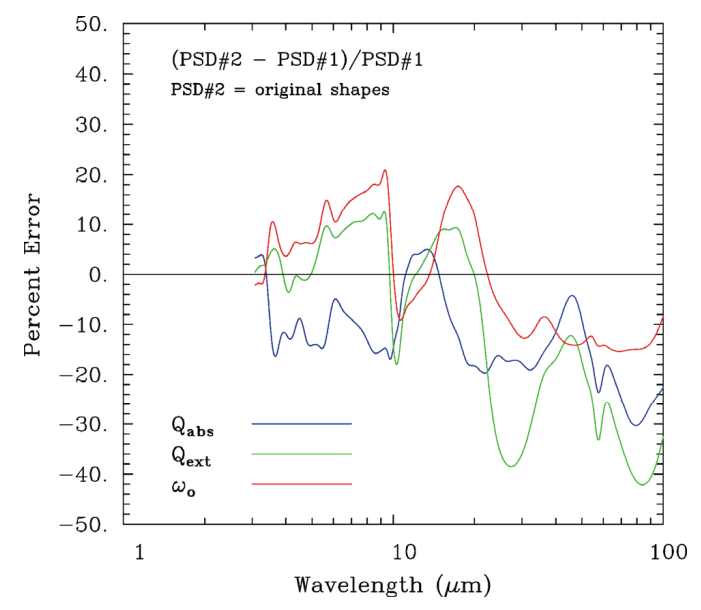

Fig. 8. Wavelength dependence of optical property errors for PSD \#2 in Fig. 4 (green curve), relative to the measured PSD (PSD \#1). Ice particle shape attributes are roughly the same in these two PSD.

$Q_{\mathrm{abs}}=\beta_{\mathrm{abs}} / A_{t}$,

$Q_{\mathrm{ext}}=\beta_{\mathrm{ext}} / A_{t}$,

where

$\beta_{\mathrm{abs}}=\int A(D) Q_{\mathrm{a}}(D, \lambda) N(D) d D$,

$\beta_{\text {ext }}=\int A(D) Q_{\mathrm{e}}(D, \lambda) N(D) d D$,

and $A(D)$ is ice particle projected area, $Q_{\mathrm{a}}(D, \lambda)$ and $Q_{\mathrm{e}}(D, \lambda)$ are absorption and extinction efficiencies for ice particles of size $D$ at wavelength $\lambda$, and $N(D)$ is the PSD for number concentration. Since the PSD projected area $A_{t}$ is defined as

$A_{t}=\int A(D) N(D) d D$,

$Q_{\text {abs }}$ and $Q_{\text {ext }}$ do not depend on the PSD area or IWC. If for a given wavelength $\beta_{\mathrm{abs}}$ and $\beta_{\text {ext }}$ depend only on $D_{\mathrm{e}}$ and IWC, then $Q_{\text {abs }}$ and $Q_{\text {ext }}$ will depend solely on $D_{\mathrm{e}}$. This is what is generally assumed when using $D_{\mathrm{e}}$ to parameterize cloud optical properties. Clearly this assumption is not valid for the results in Figs. 6 and 7. Figure 8 shows the errors in $Q_{\text {abs }}, Q_{\text {ext }}$ and the single scattering albedo $\omega_{\mathrm{o}}$ obtained for the CEPEX PSD containing the observed ice particle shapes, relative to the values from the measured PSD. In this paper the term "error" is always used in this relative context. The single scattering albedo here is defined as

$\omega_{\mathrm{o}}=1-Q_{\mathrm{abs}} / Q_{\mathrm{ext}}$.

Figure 9 shows the errors in $Q_{\text {abs }}, Q_{\text {ext }}$ and $\omega_{\mathrm{o}}$ obtained for the CEPEX PSD containing only bullet rosettes, relative to their values obtained from the measured PSD. Errors in both figures exhibit a strong spectral dependence, with errors in $Q_{\text {abs }}$ and $Q_{\text {ext }}$ having a rough tendency to be larger at 


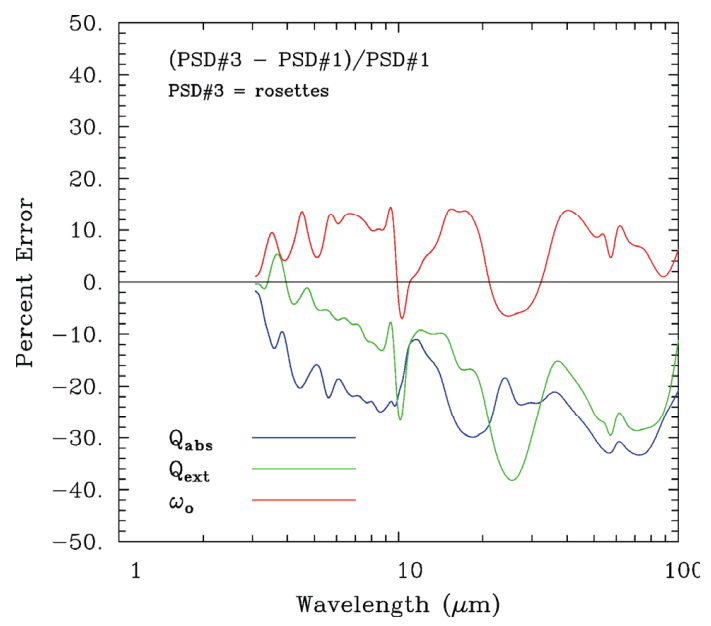

Fig. 9. Wavelength dependence of optical property errors for PSD \#3 in Fig. 4 (red curve), relative to the measured PSD (PSD \#1). PSD \#3 contains only bullet rosettes.

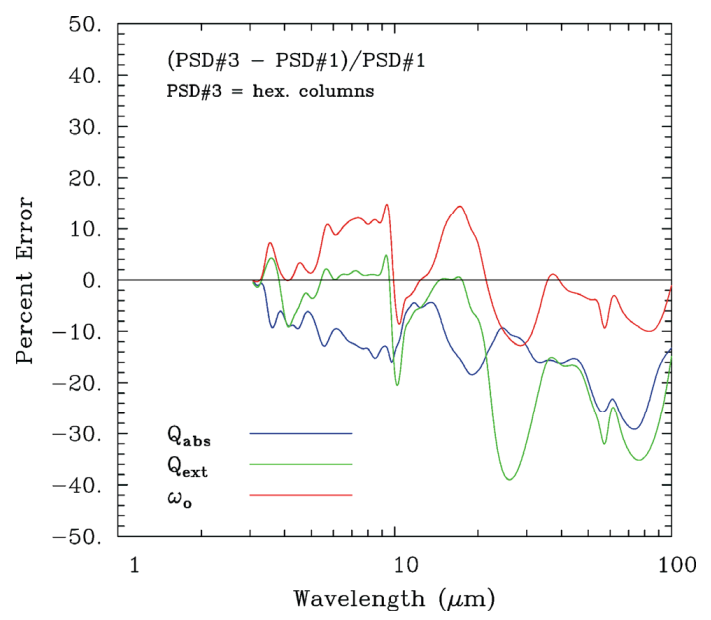

Fig. 10. Wavelength dependence of optical property errors for a PSD (not shown) having the same $D_{\mathrm{e}}$ and IWC as the measured PSD but containing only hexagonal columns, relative to the measured PSD (PSD \#1).

longer wavelengths. For climate models and remote sensing, it is not just the magnitude of the error that poses a problem, but also the rapid change in this magnitude with wavelength. For example, satellite remote sensing methods in the window region $(8.3$ to $12.5 \mu \mathrm{m})$ may difference or ratio fluxes using bands centered on $8.5 \mu \mathrm{m}$ and 11 or $12 \mu \mathrm{m}$, right where these errors fluctuate rapidly, even changing in sign. Some climate models treat solar and terrestrial radiation the same way, using $\omega_{\mathrm{o}}$ in both regions. Other climate models treat terrestrial radiation using the zero-scattering approximation, in which case only $Q_{\text {abs }}$ matters. Either way, there are large changes in $Q_{\text {abs }}$ and $\omega_{\mathrm{o}}$ with wavelength even though $D_{\mathrm{e}}$ is constant.
Ice cloud optical property parameterizations often assume hexagonal columns in their scattering calculations for single ice crystals. For this reason the analysis for bullet rosettes was repeated for hexagonal columns, with the column PSD having a $D_{\mathrm{e}}$ of $39 \mu \mathrm{m}$ and a shape (not shown) more similar to the CEPEX PSD based on observed ice particle shapes (green curve in Fig. 4). The A-D and m-D expressions assumed are listed in Table 1 . The optical property errors relative to the measured PSD are shown in Fig. 10. While somewhat less than the bullet rosette errors, the errors for hexagonal columns are still considerable.

\subsection{Optical properties of a broad PSD}

The purpose of this section is to determine whether ice cloud optical properties are sensitive to PSD shape for broader PSD having $D_{\mathrm{e}}$ values more typical of cirrus clouds. One of the mean PSD in Fig. 1, the one corresponding to -35 to $-40^{\circ} \mathrm{C}$, was selected for optical property analysis. Figure 11 features the measured PSD from Fig. 1, along with two other PSD having the same $D_{\mathrm{e}}$ and IWC. These PSD were calculated from the Mitchell PSD scheme described in Mitchell et al. (2010), which is based on PSD observations from midlatitude cirrus clouds. However, the IWC of the small mode was reduced to only $4 \%$ of the total IWC in order to match the $D_{\mathrm{e}}$ of the measured PSD. Ice particle shapes for the PSD evaluated at $-19^{\circ} \mathrm{C}$, represented by the A-D and m-D expressions in Table 1 (under ISDAC), are roughly the same in this midlatitude PSD as in the measured PSD. These A-D and $\mathrm{m}-\mathrm{D}$ expressions were derived from $2 \mathrm{D}-\mathrm{S}$ data as described in Sect. 2.1. The other PSD (evaluated at $-10.6^{\circ} \mathrm{C}$ ) is comprised entirely of hexagonal columns (having A-D and m-D expressions shown in Table 1).

The PSD optical properties were calculated from the anomalous diffraction approximation (MADA) in order to address solar wavelengths in the near-infrared. Absorption in this region increases considerably now due to the larger ice particle sizes being considered. MADA does not include the process of external reflection, and this can overestimate $Q_{\text {abs }}$ by 0 to $10 \%$ for strong absorption $\left(Q_{\text {abs }} \rightarrow 1\right)$. For the purpose of estimating photon tunneling contributions, bullet rosettes were assumed for the two PSD having the observed ice particle shapes (bullet rosettes were common in these PSD as shown in corresponding CPI images). Using Table 1 in Mitchell et al. (2006) to estimate the tunneling efficiencies $T_{\mathrm{e}}$ for bullet rosettes, $T_{\mathrm{e}}$ for the small mode was 0.7 while $T_{\mathrm{e}}$ for the large mode was 0.4 . For a given PSD size bin, the two PSD having the same particle shapes are having essentially the same $d_{\mathrm{e}}$ values, and since optical properties depend on both $d_{\mathrm{e}}$ and the tunneling contribution (which depends on $d_{\mathrm{e}}$ and $T_{\mathrm{e}}$ ), $Q_{\mathrm{a}}$ in that bin should be the same for both PSD. It is evident from Fig. 11 that the shapes of these two PSD are very different. If optical properties have a PSD shape dependence for these broader PSD, it should be evident from this comparison. The third PSD containing only 


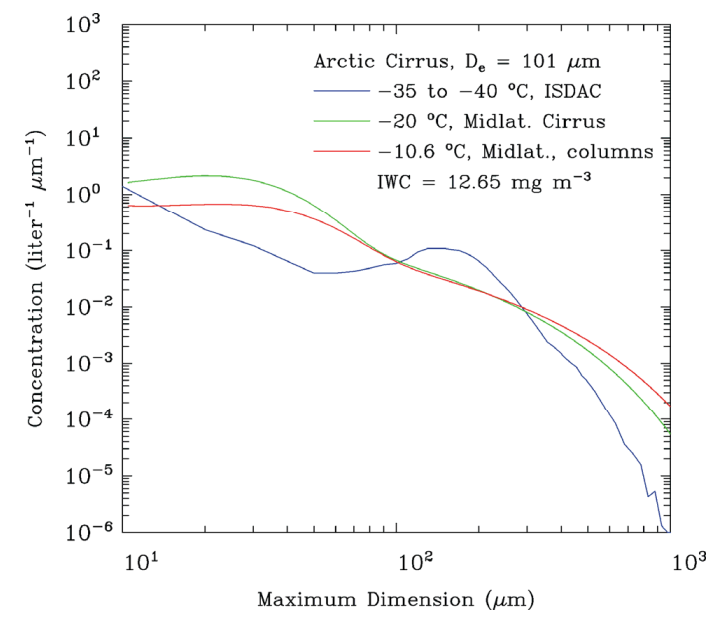

Fig. 11. Experimental design for the Arctic cirrus case study, based on the mean PSD sampled during ISDAC between -35 and $-40{ }^{\circ} \mathrm{C}$ (blue curve). The other two PSD were derived from a PSD scheme based on midlatitude cirrus data, evaluated at the indicated temperatures. The green curve contains approximately the same ice particle shapes (in terms of their mass and area attributes) as the measured PSD, while the red curve contains only hexagonal columns. All PSD are having the same $D_{\mathrm{e}}$ and IWC.

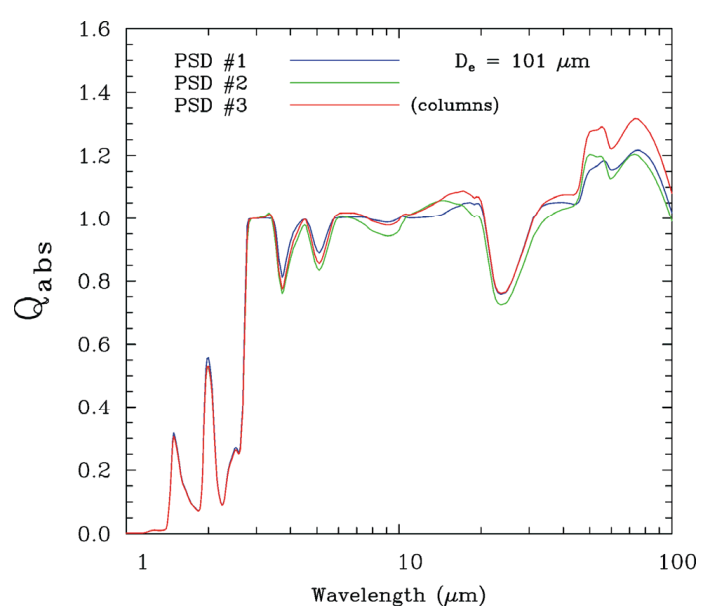

Fig. 12. Wavelength dependence of $Q_{\mathrm{abs}}$ for the 3 PSD described in Fig. 11, using the same color convention. All PSD have the same $D_{\mathrm{e}}$ and IWC. MADA ice optics were used to include the near infrared wavelengths.

hexagonal columns has a $T_{\mathrm{e}}$ for the small and large mode of 0.9 and 0.6, respectively. Thus the column PSD for a given size-bin will have crystal shape-dependent $d_{\mathrm{e}}$ and tunneling contributions that differ from the other two PSDs.

The optical properties $Q_{\mathrm{abs}}$ and $Q_{\text {ext }}$ are compared for these three PSD in Figs. 12 and 13, where PSD \#1 refers to the measured PSD, PSD \#2 has the same ice particle shapes as \#1, and PSD \#3 has only hexagonal columns. All PSD have the same $D_{\mathrm{e}}$ and IWC. Optical property errors for

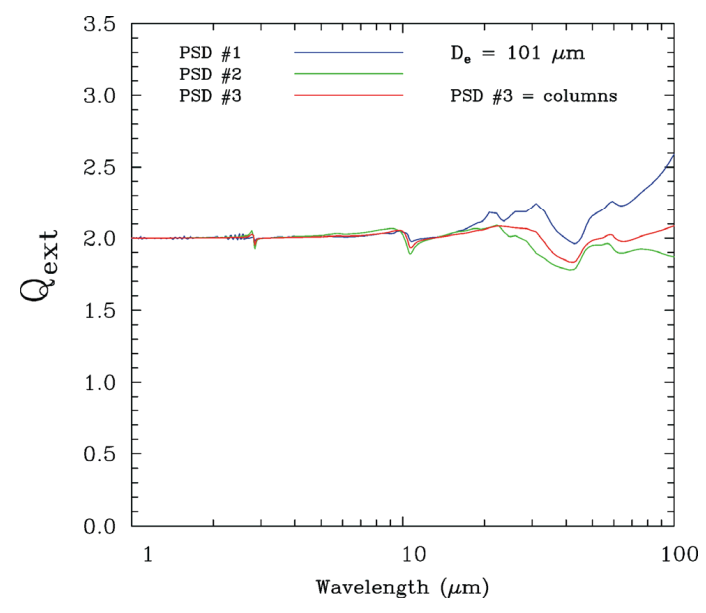

Fig. 13. Wavelength dependence of $Q_{\text {ext }}$ for the 3 PSD described in Fig. 11, using the same color convention and MADA optics. All PSD have the same $D_{\mathrm{e}}$ and IWC.

PSD \#2 relative to PSD \#1 are shown in Fig. 14. These errors are much smaller than found previously and may be acceptable for many applications regarding absorption, although errors in the far infrared for $Q_{\text {ext }}$ and $\omega_{0}$ are still considerable. This can be understood if we note that $\beta_{\text {abs }}$ and $\beta_{\text {ext }}$ can be approximated for large size parameters $\left(x=\pi D_{\mathrm{e}} / \lambda\right.$, $x>\sim 30$ ) and strong absorption as

$\beta_{\mathrm{abs}} \approx(3 / 2) \operatorname{IWC} /\left(\rho_{\mathrm{i}} D_{\mathrm{e}}\right)=A_{t}$,

$\beta_{\mathrm{ext}} \approx 3 \operatorname{IWC} /\left(\rho_{\mathrm{i}} D_{\mathrm{e}}\right)=2 A_{t}$.

Thus, it is seen that $Q_{\mathrm{abs}}, Q_{\text {ext }}$ and $\omega_{\mathrm{o}}$ are uniquely defined by $D_{\mathrm{e}}$ and IWC for large $x$ and strong absorption.

\section{Physical processes limiting the usefulness of $D_{\mathrm{e}}$}

This section seeks to understand the physical processes responsible for the differences in $Q_{\text {abs }}$ regarding PSD having the same $D_{\mathrm{e}}$ and IWC. In addition, it seeks to identify those conditions under which the $D_{\mathrm{e}}$-IWC assumption is valid.

\subsection{Photon tunneling}

This section explores the possibility that the process of wave resonance, also known as photon tunneling, contributes to the degradation of the $D_{\mathrm{e}}$-IWC assumption. Scattering resonances are comprehensively discussed in Chapter 7 of Grandy (2000), and are primarily associated with the "aboveedge" contribution of tunneling as described in Nussenzveig and Wiscombe (1980). In ice clouds, contributions to absorption and extinction from photon tunneling depend primarily on three factors: $x$, the real part of refractive index and ice particle shape (Mitchell 2000; Mitchell et al., 2006), which can contribute to tunneling in complex, non-linear ways. 


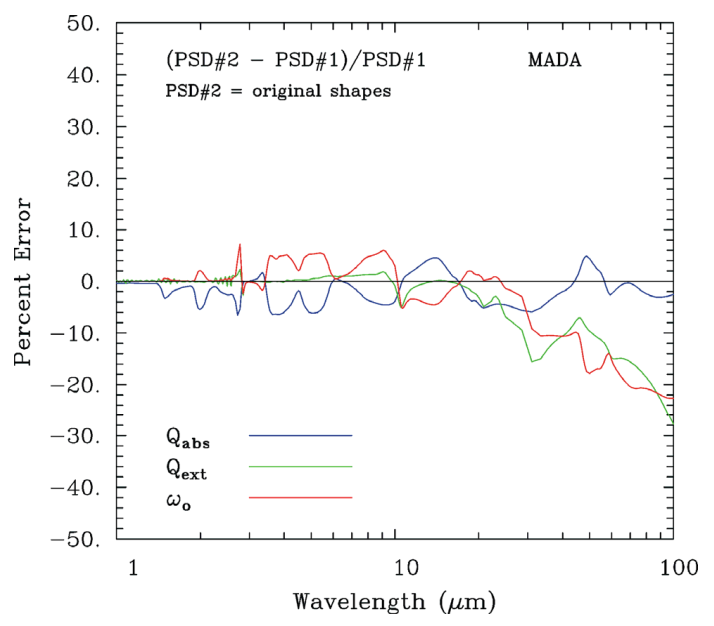

Fig. 14. Wavelength dependence of optical property errors for PSD \#2 in Fig. 11 (green curve), relative to the measured PSD (PSD \#1). Ice particle shape attributes are roughly the same in these two PSD.

Thus when tunneling contributes substantially to $Q_{\text {abs }}$ and $Q_{\text {ext }}$, it may be difficult to predict them using $D_{\mathrm{e}}$ and IWC alone. To test this hypothesis MADA can be used to predict $Q_{\text {abs }}$ and $Q_{\text {ext }}$ in the absence of tunneling, since the parameterized tunneling process can be "turned off" in MADA. MADA has been tested (Mitchell et al., 2006) and shown to agree reasonably well with ice crystal optical properties calculated from the Finite Difference Time Domain (FDTD) and T-matrix methods. The analysis described in Sect. 2.2 was repeated using MADA, and Fig. 15 reproduces Fig. 8 except Fig. 15 uses MADA when the tunneling process is inactive. It is seen that errors are considerably less without tunneling. Absorption errors were reduced by $40 \%$ or more in the window region and by $67 \%$ for $\lambda \approx 80 \mu \mathrm{m}$. Tunneling contributions are greatest when $D_{\mathrm{e}} / \lambda$ approaches unity (Mitchell 2000).

Since MADA ice optics treats any wavelength, the nearinfrared is also evaluated in Fig. 15. It is seen that errors are substantially lower in this region. This same result was found in many similar MADA calculations (not shown) regarding the near-IR. This is partly because $x$ is larger and tunneling contributions are negligible for $x>\sim 50$. But this may also be due to absorption being primarily volume dependent in this region, as described in the next subsection.

\subsection{Volume and area dependent absorption}

In this section we test the hypothesis that for ice clouds, in spectral regions where either volume or area dependent absorption dominate, $D_{\mathrm{e}}$ and IWC can uniquely describe ice cloud optical properties, at least as far as $Q_{\text {abs }}, Q_{\text {ext }}$ and $\omega_{\mathrm{o}}$ are concerned. Volume dependent absorption will be addressed first.

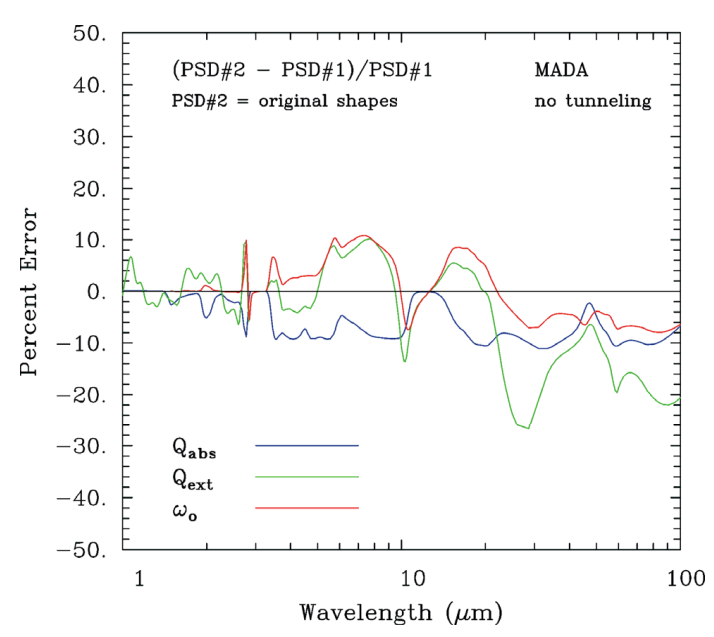

Fig. 15. Same as in Fig. $8\left(D_{\mathrm{e}}=39 \mu \mathrm{m}\right)$ but without the process of photon tunneling. MADA optics was used here to remove the tunneling process.

When tunneling contributions are negligible, absorption can be approximated using anomalous diffraction theory (ADT):

$Q_{\mathrm{a}} \approx 1-\exp \left(-4 \pi n_{\mathrm{i}} d_{\mathrm{e}} / \lambda\right)$,

where $d_{\mathrm{e}}=V / A$ and $V=$ ice particle volume at bulk ice density $\rho_{\mathrm{i}}=\mathrm{m} / \rho_{\mathrm{i}}$. When the magnitude of the exponential argument is sufficiently small, the exponential term in Eq. (10) can be approximated by a series expansion as shown in Mitchell and Arnott (1994), giving $Q_{\mathrm{a}}$ for volume dependent absorption:

$Q_{\mathrm{a}} \approx 4 \pi n_{\mathrm{i}} V / \lambda A$.

Substituting Eq. (11) into Eq. (4), and noting that $V=\mathrm{m} / \rho_{\mathrm{i}}$, the purely volume dependent absorption coefficient is:

$\beta_{\mathrm{abs}}=\left(4 \pi n_{\mathrm{i}} / \rho_{\mathrm{i}} \lambda\right) \int m(D) N(D) d D$,

where the integral is simply the IWC. Thus,

$\beta_{\mathrm{abs}}=4 \pi n_{\mathrm{i}} \mathrm{IWC} / \rho_{\mathrm{i}} \lambda$.

Even though absorption in the near infrared $(\lambda<2.7 \mu \mathrm{m})$ is considerable in Fig. 12, volume dependent absorption dominates in this region and absorption errors are small. For extinction under these same conditions, when $x$ is large, $\beta_{\text {ext }}$ is well described by Eq. (9). Thus for solar radiation at wavelengths $<2.7 \mu \mathrm{m}$, when volume dependent absorption generally dominates $\left(n_{\mathrm{i}}<\sim 10^{-3}\right)$ and $x>\sim 30, \beta_{\mathrm{abs}}, \beta_{\mathrm{ext}}$ and $\omega_{\mathrm{o}}$ are uniquely defined by IWC and $D_{\mathrm{e}}$.

Area dependent absorption occurs when the exponential argument in Eq. (10) is sufficiently large such that $Q_{\mathrm{a}} \approx 1$. For these conditions and when $x>30$, Eqs. (8) and (9) are valid approximations and $\beta_{\mathrm{abs}}, \beta_{\mathrm{ext}}$ and $\omega_{\mathrm{o}}$ are uniquely defined 


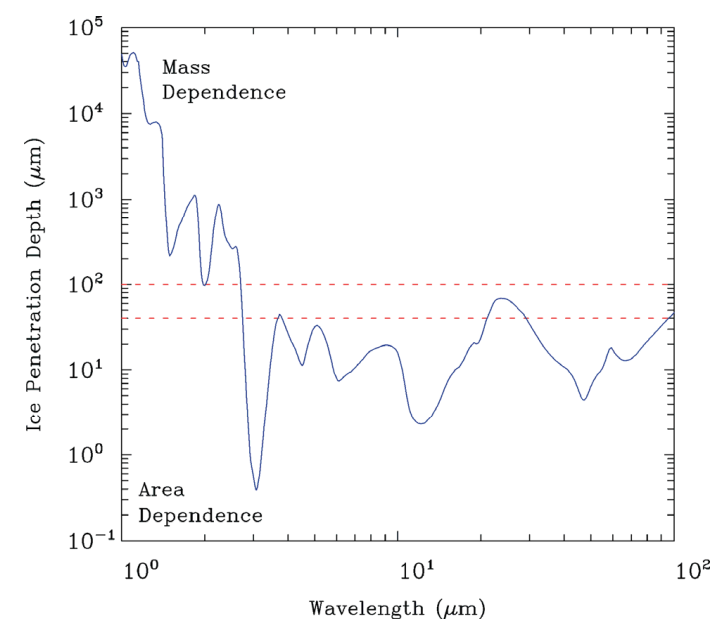

Fig. 16. Wavelength dependence for the radiation penetration depth into bulk ice. The two horizontal dashed lines represent $D_{\mathrm{e}}$ for the two cases considered here. Regions of purely mass and area dependent absorption are indicated.

by IWC and $D_{\mathrm{e}}$. However, when $1<x<30$, photon tunneling contributions to $\beta_{\mathrm{abs}}, \beta_{\mathrm{ext}}$ and $\omega_{\mathrm{o}}$ are considerable and wavelength dependent, making it more difficult to predict these properties from $D_{\mathrm{e}}$ and IWC alone. Even when $Q_{\mathrm{abs}}$ as predicted by Eq. (10) is $\sim 1.0$, the actual $Q_{\text {abs }}$ with tunneling included may vary from 1.0 to 1.4. In addition, $\beta_{\text {ext }}$ and thus $\omega_{0}$ may be subject to strong wave interference phenomena for $x<\sim 15$. Thus for $1<x<30, \beta_{\mathrm{abs}}, \beta_{\mathrm{ext}}$ and $\omega_{\mathrm{o}}$ are not uniquely defined by $D_{\mathrm{e}}$ and IWC.

\subsection{Transition absorption}

Transition absorption here refers to absorption that is partially volume and partially area dependent. It is neither predominately volume nor area dependent, but represents a transition between these two states. In this absorption category, it is postulated that ice cloud optical properties are not well defined solely in terms of $D_{\mathrm{e}}$ and IWC, and this hypothesis is tested in this section. To do this, it is instructive to calculate the radiation penetration depth into bulk ice. For zero scattering,

$d I(\lambda) / I_{\mathrm{o}}(\lambda)=-k_{\mathrm{i}}(\lambda) d L$,

where $I_{0}(\lambda)=$ incident radiance normal to bulk ice, $I(\lambda)=$ radiance within the ice, $\mathrm{L}=$ penetration distance of radiation into ice and $k_{\mathrm{i}}(\lambda)$ is the absorption coefficient for bulk ice (Moosmüller et al., 2009):

$k_{\mathrm{i}}=4 \pi n_{\mathrm{i}} / \lambda$.

Integrating Eq. (14) and then evaluating for the e-folding ice penetration depth (i.e. $\mathrm{I}(\lambda) / \mathrm{I}_{0}(\lambda)=1 / \mathrm{e}$ ), the distance radi- ation penetrates into bulk ice to produce an attenuation of $1 / \mathrm{e}$ is determined:

$\Delta L=\lambda / 4 \pi n_{\mathrm{i}}$.

This ice penetration depth is plotted as a function of wavelength $\lambda$ in Fig. 16. This curve represents the approximate value $D_{\mathrm{e}}$ would need to have to enter into the "transition absorption regime" from the volume dependent regime. The two red dashed lines represent the $D_{\mathrm{e}}$ values considered in this paper. For a given horizontal $D_{\mathrm{e}}$ line, the further the $\Delta L$ line drops below the $D_{\mathrm{e}}$ line, the more absorption becomes area dependent until at some distance below the $D_{\mathrm{e}}$ line absorption is purely area dependent. Conversely, the more the $\Delta L$ line rises above a given $D_{\mathrm{e}}$ line, the more absorption becomes volume dependent until absorption becomes purely volume dependent. The $\Delta L$ line itself appears to lie in a region dominated by volume dependent absorption but within the "transition zone", as is discussed below.

When comparing two PSD having the same $D_{\mathrm{e}}$ and IWC, it follows from Sect. 3.2 that differences in their optical properties would be negligible when absorption is purely volume or area dependent, provided tunneling is absent. In Fig. 16 we see that local maximums for area dependent absorption occur for $\lambda$ at 3, 4.4, 6, 12 and $45 \mu \mathrm{m}$. In Fig. 15, minimums in $Q_{\text {abs }}$ errors occur at these same wavelengths, proportional to the maximums for area dependent absorption in Fig. 16. This suggests that the ice penetration depth is related to the $Q_{\text {abs }}$ percent error when tunneling is removed, which indeed it is as shown in Fig. 17. Also shown in Fig. 17 is the same analysis for PSD \#2 absorption errors for the case when $D_{\mathrm{e}}=101 \mu \mathrm{m}$ when tunneling is absent (red circles). The region where the $D_{\mathrm{e}}$-IWC assumption breaks down due to transition absorption can now be clearly identified in Fig. 17 in terms of the ice penetration depth. Without removing tunneling, these patterns are less coherent, and if the ice particle shape is changed, the relationship shown in Fig. 17 is largely erased since the tunneling behavior between PSDs is not the same. More discussion is provided in the ACPD version of this paper.

Figure 17 shows that the peak $Q_{\text {abs }}$ error occurs $\sim 1 / 2$ $D_{\mathrm{e}}$ in the $39 \mu \mathrm{m}$ example (blue circles) and $\sim 1 / 3 D_{\mathrm{e}}$ for the $101 \mu \mathrm{m}$ example (red circles). From these examples it appears that the transition absorption error is maximum when $\Delta L$ is roughly $1 / 2$ to $1 / 3$ of the $D_{\mathrm{e}}$ value. The larger $D_{\mathrm{e}}$ case exhibits more area absorption at lower $\Delta L$ and more transition absorption at higher $\Delta L$ as intuitively expected. The reason for the different amplitudes in peak absorption error is not clear, although we speculate that this is due to the shapes of the PSD being compared. The range over which transition absorption is important spans at least an order of magnitude in ice penetration depth. For terrestrial radiation and narrow PSDs, transition absorption tends to dominate, whereas area dependent and transition absorption (with less tunneling) tend to dominate for broad PSD. Thus ice cloud optical 


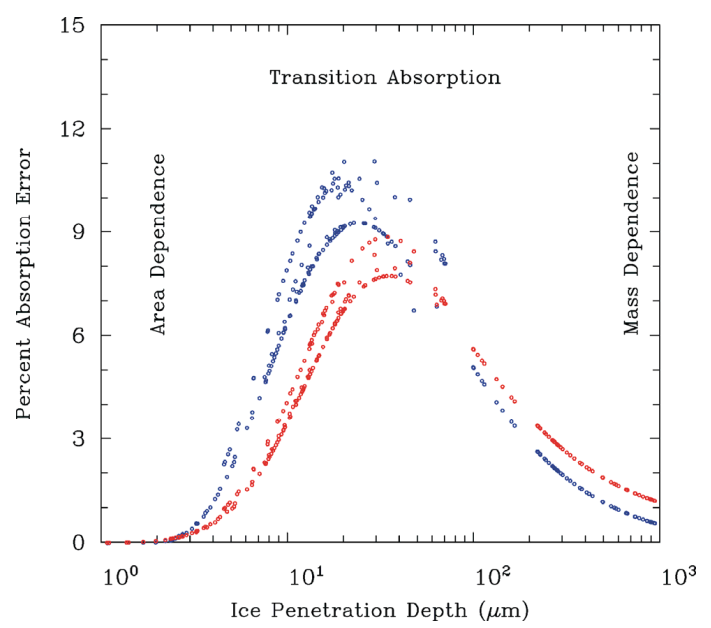

Fig. 17. Absolute values of $Q_{\text {abs }}$ errors (relative to the measured PSD) related to the ice penetration depth at corresponding wavelengths, where blue is for the $D_{\mathrm{e}}=39 \mu \mathrm{m}$ case and red is for the $D_{\mathrm{e}}=101 \mu \mathrm{m}$ case. In each case the two PSD compared have the same ice particle shapes and tunneling contributions were removed from their optical properties so that transition absorption could be examined in isolation regarding PSD shape differences.

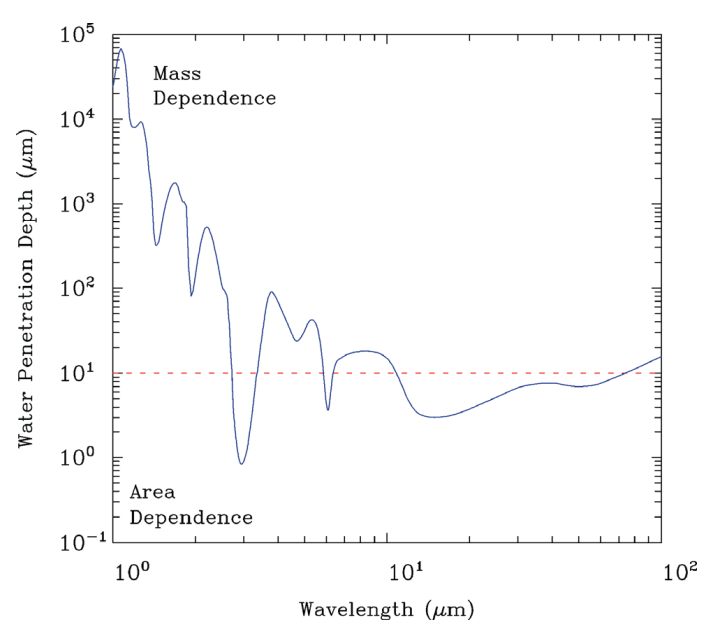

Fig. 18. Wavelength dependence for the radiation penetration depth into bulk liquid water. The horizontal dashed line represents a typical $D_{\mathrm{e}}$ value for non-precipitating water clouds.

properties not only depend on $D_{\mathrm{e}}$ and IWC, but also depend on the PSD shape when transition absorption dominates and when $1<x<30$ (i.e. tunneling contributions are significant).

\subsection{Liquid water clouds}

Many studies have shown that the optical properties of liquid water clouds are well described by $D_{\mathrm{e}}$ and the liquid water content (LWC). The question naturally comes whether transition absorption could limit the usefulness of $D_{\mathrm{e}}$ in liquid water clouds. Figure 18 shows the liquid water penetration depth in the near infrared and for terrestrial radiation using the imaginary part of the refractive index for liquid water. The horizontal dashed line at $10 \mu \mathrm{m}$ is representative of typical $D_{\mathrm{e}}$ values in water clouds. It is evident that transition absorption is common for some regions regarding terrestrial radiation, and tunneling contributions may be greater for water clouds than ice clouds (Mitchell 2000; M2002). Hence one might expect to find conditions in water clouds where cloud optical properties are not well defined by $D_{\mathrm{e}}$ and LWC. However, in M2002, it was shown that when the PSD was relatively narrow in water clouds, PSD optical properties were accurately defined by $D_{\mathrm{e}}$ and LWC based on Mie theory, and when the PSD were relatively broad, the optical properties were less well defined by $D_{\mathrm{e}}$ and LWC, but still the errors were small in comparison to those found in this study. The reason from M2002 is that the PSD broadness or dispersion in water clouds is far less than found in ice clouds, even for relatively broad cloud droplet size spectra. Ice cloud PSD tend to be exponential, super-exponential or bimodal (e.g. Jensen et al., 2009; Lawson et al., 2010; Mitchell et al., 2010; Zhao et al., 2010), whereas cloud droplet size spectra tend to be monomodal and subexponential. For the PSD of water clouds, $D_{\mathrm{e}}$ is more representative of cloud element photon paths and thus better describes the cloud optical properties. While this argues that water cloud optical properties are well defined by $D_{\mathrm{e}}$ and LWC, more research is needed.

\section{Summary and implications}

It has been shown that under some conditions, ice cloud optical properties are not well defined by $D_{\mathrm{e}}$ and IWC, but are also a function of the shape of the ice particle size distribution (PSD). The PSD shape matters most when (1) absorption is neither volume (i.e. mass) nor area dependent, what we call transition absorption, and (2) when size parameter $x$ is between $\sim 1$ and 30 , where photon tunneling contributions are significant. These conditions are best satisfied for terrestrial radiation when $D_{\mathrm{e}}<\sim 60 \mu \mathrm{m}$ (i.e. PSD are relatively narrow). Treating optical properties solely in terms of $D_{\mathrm{e}}$ and IWC may lead to errors of 24\%, 26\% and 20\% for terrestrial radiation in the window region regarding $Q_{\mathrm{abs}}, Q_{\mathrm{ext}}$ and $\omega_{\mathrm{o}}$, respectively. Outside the window region, errors may reach $33 \%$ and $42 \%$ regarding $Q_{\text {abs }}$ and $Q_{\text {ext }}$. It is not just the magnitude of the errors that are problematic; these errors exhibit a strong spectral dependence which may produce misleading results in remote sensing and other applications concerned with the wavelength dependence of radiation.

It was shown that changing the ice particle shape imposes a change in PSD shape when $D_{\mathrm{e}}$ and IWC are being conserved, and that this results in altering the PSD optical properties. In this way ice optical properties depend on ice particle shape even when $D_{\mathrm{e}}$ and IWC are constant.

When comparing optical properties from PSD having the same $D_{\mathrm{e}}$, IWC and ice particle shapes but different PSD 
shapes, absorption errors that result only from "transition absorption" peak when the ice penetration depth is roughly $1 / 2$ to $1 / 3$ of the $D_{\mathrm{e}}$ value. In this way, spectral regions in which the traditional $D_{\mathrm{e}}$-IWC assumption is likely to be poor can be identified for a given $D_{\mathrm{e}}$. The range over which transition absorption is important spans at least an order of magnitude in ice penetration depth. This understanding was made possible by removing the absorption contribution of photon tunneling, which would normally obscure these relationships.

Recently it has been demonstrated that historical PSD measurements in ice clouds have suffered from the problem of ice particle shattering, where ice particles impact the inlet tube of the sampling probe and shatter, often increasing the concentrations of small ice crystals by 1-2 orders of magnitude (McFarquhar et al., 2007; Jensen et al., 2009; Lawson et al., 2010; Mitchell et al., 2010; Zhao et al., 2010). Correcting this artifact problem often changes the shape of the measured PSD. Since parameterizations of ice cloud optical properties used in climate models are generally developed from $\sim 30$ historical PSD measurements, it is possible that their predicted optical properties would change if the PSD they assume were based on the more recent (reduced artifact) measurements. This concern is most acute for $D_{\mathrm{e}}<\sim 60 \mu \mathrm{m}$.

One possible way to address this problem is to use the MADA ice optics scheme directly in a climate model. MADA is formulated in terms of the PSD parameters (assuming a gamma distribution) and the ice particle mass- and area-dimension power laws that represent the ice particle shape mixture and thus it is not vulnerable to this parameterization problem. MADA cannot predict the scattering phase function or asymmetry parameter $g$, but at terrestrial wavelengths $g$ depends mostly on the area-cross section of an ice particle resulting in strong forward scattering at most cirrus particle sizes, and thus may be adequately represented by conventional ice optics schemes. Another approach for describing ice cloud optical properties in climate models without the use of $D_{\mathrm{e}}$ is given in Baran et al. (2009).

The findings of this study may also be relevant to the field of remote sensing if the remote sensing algorithms that retrieve cloud physical properties assume that the cloud optical properties are uniquely defined by $D_{\mathrm{e}}$ and IWC. Given this assumption is not always true, a priori PSD models used in remote sensing retrievals should be based on the newer, more accurate PSD measurements.

Acknowledgements. This work was supported by the Office of Science (BER), US Department of Energy, Grant No. DE-FG0206ER64201. This work was also supported from funding provided to SPEC Incorporated under NASA Radiation Sciences Program Grant No. NNX07AK81G, and US Department of Energy Atmospheric Radiation Measurement Program Grant No. DESC0004024. Prior to this research, conversations with Eli Mlawer led to deeper questioning of the $D_{\mathrm{e}}$-IWC assumption, providing the motivation for this paper. These conversations with Eli are gratefully appreciated.
Edited by: Q. Fu

\section{References}

Baker, B. A., Korolev, A., Lawson, R. P., O'Conner, D., and Mo, Q.: Drop size distributions and the lack of small drops in RICO rainshafts, J. Appl. Meteorol., 48, 616-623, doi:10.1175/2008JAMC1934.1, 2009a.

Baker, B., Mo, Q., Lawson, R. P., O'Conner, D., and Korolev, A.: The effects of precipitation on cloud droplet measurement devices, J. Atmos. Ocean. Technol., 26, 1404-1409, doi:10.1175/2009JTECA1191.1, 2009b.

Baran, A. J., Connolly, P. J., and Lee, C.: Testing an ensemble model of cirrus ice crystals using midlatitude in situ estimates of ice water content, volume extinction coefficient and the total solar optical depth, J. Quant. Spectros. Radiat. Trans., 110, 1579-1598, 2009.

Baumgardner, D., Jonsson, H., Dawson, W., O'Connor, D., and Newton, R.: The cloud, aerosol and precipitation spectrometer: a new instrument for cloud investigations, Atmos. Res., 59-60, 251-264, 2001.

Hansen, J. E. and Travis, L. D.: Light scattering in planetary atmospheres, Space Sci. Rev., 16, 527-610, 1974.

Heymsfield, A. J., Bansemer, A., Field, P. R., Durden, S. L., Stith, J. L., Dye, J. E., Hall, W., and Grainger, C. A.: Observations and parameterizations of particle size distributions in deep tropical cirrus and stratiform precipitating clouds: Results from in situ observations in TRMM field campaigns. J. Atmos. Sci., 59, 3457-3491, 2002.

Field, P. R., Heymsfield, A. J., Bansemer, A.: Shattering and particle interarrivaltimes measured by optical array probes in ice clouds, J. Atmos. Ocean. Technol., 23, 1357-1371, 2006.

$\mathrm{Fu}, \mathrm{Q}$.: An accurate paramterization of the solar radiative properties of cirrus clouds for climate models, J. Climate, 9, 2058-2082, 1996.

Fu, Q., Yang, P., and Sun, W. B.: An accurate parameterization of the infrared radiative properties of cirrus cloud for climate models, J. Climate, 11, 2223-2237, 1998.

Grandy Jr., W. T.: Scattering of waves from large spheres, Cambridge University Press, Cambridge, UK, 370 pp., 2000.

Grenfell, T. C. and Warren, S. G.: Representation of a non-spherical ice particle by a collection of independent spheres for scattering and absorption of radiation, J. Geophys. Res., 104, 3169731709, 1999.

Ivanova, D.: Cirrus clouds parameterization for global climate models (GCMs) and North American (Mexican) monsoon modeling study. Ph.D. dissertation, University of Nevada, Reno, USA, 181 pp., 2004.

Jensen, E. J. and Coauthors: On the importance of small ice crystals in tropical anvil cirrus. Atmos. Chem. Phys., 9, 5519-5537, doi:10.5194/acp-9-5519-2009, 2009.

Knollenberg, R. G.: Techniques for probing cloud microstructure. Clouds: Their Formation, Optical Properties and Effects, edited by: Hobbs, P. V. and Deepak, A., Academic Press, 15-91, 1981.

Korolev, A. and Isaac, G. A.: Roundness and aspect ratios of particles in ice clouds, J. Atmos. Sci., 60, 1795-1808, 2003.

Korolev, A. and Isaac, G. A.: Shattering during sampling by OAPs and HVPS. Part I: Snow particles, J. Atmos. Ocean. Tech., 22, 528-542, 2005. 
Korolev, A., Emery, E. F., Strapp, J. W., Cober, S. G., Isaac, G. A., Wasey, M., and Marcotte, D.: Small ice particles in tropospheric clouds: fact or artifact? Airborne Icing Instrumentation Evaluation Experiment, Bull. Amer. Meteorol. Soc., early online release, doi:10.1175/2010BAMS3141.1, 2010.

Lawson, R. P., Baker, B., Pilson, B., and Mo, Q.: In situ observations of the microphysical properties of wave, cirrus and anvil clouds. Part 2: Cirrus clouds, J. Atmos. Sci., 63, 3186-3203, 2006.

Lawson, R. P., Jensen, E. J., Mitchell, D. L., Baker, B., Mo, Q., and Pilson, B.: Microphysical and radiative properties of tropical clouds investigated in TC4 and NAMMA, J. Geophys. Res., 115, D00J08, doi:10.1029/2009JD013017, 2010.

McFarquhar, G. M., Um, J., Freer, M., Baumgardner, D., Kok, G., and Mace, G.: The importance of small ice crystals to cirrus properties: Observations from the Tropical Warm Pool International Cloud Experiment (TWP-ICE), Geophys. Res. Lett., 34, L13803, doi:10.1029/2007GL02986, 2007.

McFarquhar, G. M. and Heymsfield, A. J.: The definition and significance of an effective radius for ice clouds, J. Atmos. Sci., 55, 2039-2052, 1998.

Mitchell, D. L. and Arnott, W. P.: A model predicting the evolution of ice particle size spectra and radiative properties of cirrus clouds. Part II: Dependence of absorption and extinction on ice crystal morphology, J. Atmos. Sci., 51, 817-832, 1994.

Mitchell, D. L.: Use of mass- and area-dimensional power laws for determining precipitation particle terminal velocities, J. Atmos. Sci., 53, 1710-1723, 1996.

Mitchell, D. L., Macke, A.m and Liu, Y.: Modeling cirrus clouds. Part II: Treatment of radiative properties. J. Atmos. Sci., 53, 2952-2966, 1996.

Mitchell, D. L.: Parameterization of the Mie extinction and absorption coefficients for water clouds, J. Atmos. Sci., 57, 1311-1326, 2000.

Mitchell, D. L.: Effective diameter in radiation transfer: General definition, applications and limitations, J. Atmos. Sci., 59, 23302346, 2002.
Mitchell, D. L., Baran, A. J., Arnott, W. P., and Schmitt, C.: Testing and comparing the modified anomalous diffraction approximation, J. Atmos. Sci., 63, 2948-2962, 2006.

Mitchell, D. L., d'Entremont, R. P., and Lawson, R. P.: Inferring cirrus size distributions through satellite remote sensing and microphysical databases, J. Atmos. Sci., 67, 1106-1125, 2010.

Moosmüller, H., Chakrabarty, R. K., and Arnott, W. P.: Aerosol light absorption and its measurement: A review, J. Quant. Spectrosc. Radiat. Transfer, 110, 844-878, 2009.

Nussenzveig, H. M. and Wiscombe, W. J.: Diffraction as tunneling, Phys. Rev. Lett., 59, 1667-1670, 1987.

Slingo, A. and Schrecker, H. M.: On the shortwave radiative properties of stratiform water clouds, Q. J. Roy. Meteorol. Soc., 108, 407-426, 1982.

Slingo, A.: A GCM parameterization for the shortwave radiative properties of water clouds, J. Atmos. Sci., 46, 1419-1427, 1989.

Sun, W., Hu, Y., Lin, B., Liu, Z., and Videen, G.: The impact of ice cloud microphysics on the uncertainty of ice water content retrievals, J. Quant. Spectrosc. Radiat. Transfer, 112, 189-196, 2011.

Warren, S. G., and Brandt, R. E.: Optical constants of ice from the ultraviolet to the microwave: A revised compilation, J. Geophys. Res., 113, D14220, doi:10.1029/2007JD009744, 2008.

Yang, P., Gao, B.-C., Baum, B. A., Hu, Y. X., Wiscombe, W. J., Tsay, S.-C., Winker, D. M., and Nasiri, S. L.: Radiative properties of cirrus clouds in the infrared $(8-13 \mu \mathrm{m})$ spectral region, J. Quant. Spectrosc. Radiat. Transfer, 70, 473-504, 2001.

Yang, P., Wei, H., Huang, H-L., Baum, B. A., Hu, Y. X., Kattawar, G. W., Mishchenko, M. I., and Fu, Q.: Scattering and absorption property database for nonspherical ice particles in the nearthrough far-infrared spectral region, Appl. Opt., 44, 5512-5523, 2005.

Zhao, Y., Mace, G., and Comstock, J.: The occurrence of particle size distribution bimodality in middle latitude cirrus as inferred from ground-based remote sensing data, J. Atmos. Sci., early online release, doi:10.1175/2010JAS3354.1, 2010. 